\title{
Türkiye Bal Arılarında Ciddi Tehlike; Nosemosis
}

\author{
Mehmet Özüiçli, Levent Aydın
}

Uludağ Üniversitesi Veteriner Fakültesi, Parazitoloji Anabilim Dalı, Nilüfer - Bursa

Gönderilme: 27.04.2018 Kabul: 03.07.2018

\begin{abstract}
Özet
Nosema apis ve Nosema cerenae ergin bal arılarında (Apis mellifera) Nosemosis'e neden olur ve bu etkenler ergin arıların bağırsak sistemine yerleşir. Nosemosis en yaygın arı hastalıklarından birisidir ve dünya çapında önemli arı kayıplarına neden olur. Bu hastalık direkt olarak; sindirim sistemi bozukluklarına, arıların ortalama ömrünün azalmasına, koloni sayısının azalmasına neden olur ve indirekt olarak; bal üretiminin ve polen toplamanın azalmasına ve kolonide önemli kış kayıplarına neden olur. Bu hastalık bakteriyel, protozoon ve viral hastalıklarla birlikte görülebilir bu durum arı kolonisi sağlığını, arı ürünlerini ve üretimini olumsuz yönde etkiler. Bu derlemede Nosema hastalığının ergin arılarda önemi ve Nosemosis kontrol programına vurgu yapılmıştır.

Anahtar Kelimeler: Nosemosis, Apis mellifera, Hastalık, Kontrol

\section{Abstract \\ Serious Threat for Turkish Honeybees; Nosemosis}

Nosemosis is one of the most prevalent bee diseases that cause significant bee losses worldwide. The causative agents of Nosemosis in adult honey bees (Apis mellifera) are Nosema apis and Nosema cerenae and these agents invade intestines of adult bees. This disease causes digestive tract disorders, reducing the lifespan of bees, decreasing bee colony number directly, indirectly, decreasing honey production and pollen collecting and important bee's colony losses in a dormant season. It may be seen together with bacterial, protozoal and viral diseases. This circumstance negatively affects the health of bee colonies, bee products and productivity. In this review, the importance of Nosema disease in adult bees and control programme of Nosemosis are emphasized.
\end{abstract}

Key Words: Nosemosis, Apis mellifera, Disease, Control

\section{Giriş}

Arıc1lık günümüzde ülkemizde ve dünyada önemli bir ticaret ve iş kolu olarak ortaya çıkmaktadır. Özellikle arıların polinasyonla birlikte sağladıkları önemli bir ekonomik katkı vardır. Bu bağlamda Dünya Arıcılar Birliği Başkanı Philip McCabe'in son açılamasına göre ABD'de polinasyonun ülke ekonomisine katkısı 115 milyar dolar, Avrupa ekonomisine katkısı 42 milyar dolardır. Bu rakamlara bakılarak arıcıllğın dünya üzerinde ne kadar önem arz eden bir iş kolu olduğu anlaşılmaktadır. Polinasyonun yanında arı ürünleri; başta bal olmak üzere, polen, propolis, arı sütü, arı zehri, apilarnil gıda ve ilaç sanayisinde kullanılmaktadır. Her canlıda olduğu gibi bal arılarında da birtakım hastalık etkenleri gözlemlenmekte; koloni sağlığı ve devamlılığını olumsuz yönde etkilemektedir. CCD’ye (Colony Collapse Disorder) birçok faktör neden olabilir (Cox-Foster ve ark., 2007). Bu nedenlerden en önemlilerinden biri de Nosema cinsinde yer alan Nosema apis ve N. ceranae etkenleridir (Paxton, 2010; Chaimanee ve ark., 2010). 
Mikrosporodial entomopatojenler arasında yer alan yoluyla alınmasıyla enfekte olur (Webster ve ark., 2004; Nosemosis etkenleri, bal ve bombus arıları ile ipek Chen ve ark., 2008). Arı bağırsaklarında sporların optiböceklerini patolojik, ekolo-jik ve ekonomik olarak mal gelişimi 30-34 ${ }^{\circ} \mathrm{C}$ 'dir ve sporlar yedi aydan fazla aktif etkileyerek Veteriner Hekimliğin ilgi alanına girmiştir. Bal kalabilir (Şekil 1). N. ceranae ergin bal arılarında herhangi arılarında ani kovan sönmesi ola-rak adlandırılan sendrom bir klinik semptom göstermeden genellikle kovan üzerinde yapılan araştırmalar Nosemosis hakkındaki dışında hızlı ölümlere neden olur (Higes ve ark., 2007; bilgileri arttırmıştır. N. cerenae'nın ani koloni kayıplarıyla Paxton ve ark., 2007; Chen ve ark., 2009; Forsgren ve ilgili olduğu birçok ülkede yapılan araştırmalarla kayıt Fries, 2010). N. ceranae enfeksiyonlarında insidans yıl altına alınmıştır. N. cerenae'ya bağlı arı kayıpları ishal boyu aynı kalır, bu özellik $N$. apis enfeksiyonlarından $N$. semptomları ve ölü arılar bulunmadan mey-dana geldiği ceranae enfeksiyonlarını ayıran en önemli noktadır (Klee için arıcılar arasında sessiz ölüm olarak ad-landırılır. Son yıllarda dünya çapında arı ölümlerinde ciddi artışlar gözlemlenmiştir. Arı popülasyonundaki bu hızlı düşüş viral, mantar, parazitik hastalıklar, pestisit zehirlen-mesi, tek yönlü tarım, polen kıtlığıyla ilişkilidir (Aydın ve ark., 2006; Chen ve ark., 2008)

\section{Etiyoloji}

Âlem: Mantarlar

Şube: Mikrosporidia

Sinif: Dihaplophasea

Dizi: Dissociodihaplophasida

Aile: Nosematidae

Cins: Nosema

Tür: N.ceranae ve N. apis

$\mathrm{Bu}$ hastalık etkenleri zorunlu hücre içi mantarlar olan mikrosporidia şubesinde yer alırlar. N. apis'in Zander (1909) tarafindan Batı bal arılarında (Apis mellifera) ortaya çıkarıldığı bilinmektedir. Buna ek olarak 1994 yılında Doğu bal arılarında (Apis cerana Fabricus) N. apis'e benzer bir mikrosporidia olan $N$. ceranae tanımlanmıştır (Fries, 2010). Yapılan çalışmalar ile A. cerana'da parazitlenen N. ceranae'nın günümüzde $A$. mellifera’ya uyum sağladığı ve $N$. apis'in yerini alarak en baskın hastalık etkeni olduğu bilinmektedir. N. ceranae'nın N. apis'e göre daha şiddetli enfeksiyon ve daha yüksek ölüm oranı oluşturduğu ortaya konmuştur (Forsgren ve Fries, 2010). N. ceranae, son yillarda birçok etken ile birlikte "Colony Collapse Disorder" (CCD) olarak adlandırılan koloni kayıplarının nedenle-rinden biri olarak görülmektedir. Etkenler kolaylıkla spor oluşturmakta ve genelde spor formunda bulunmaktadır. N. apis'in sporları oval şekilli, 4-6 $\mu \mathrm{m}$ uzunluğunda, $2-4 \mu \mathrm{m}$ genişliğinde, $N$. ceranae'nin sporları ise daha küçük olarak 3.3 - $5.5 \mu \mathrm{m}$ uzunluğunda ve 2.3 - 3 $\mu \mathrm{m}$ genişli-ğindedir. Sporlar dışkıda, ölü arıda ve balda 1 yll, toprakta $2-3$ ay enfektif olarak kalabilir (Forsgren ve Fries, 2010).

\section{Klinik Belirtiler}

Arılar Nosema sporlarıyla enfekte gıdaların ve suyun ağız

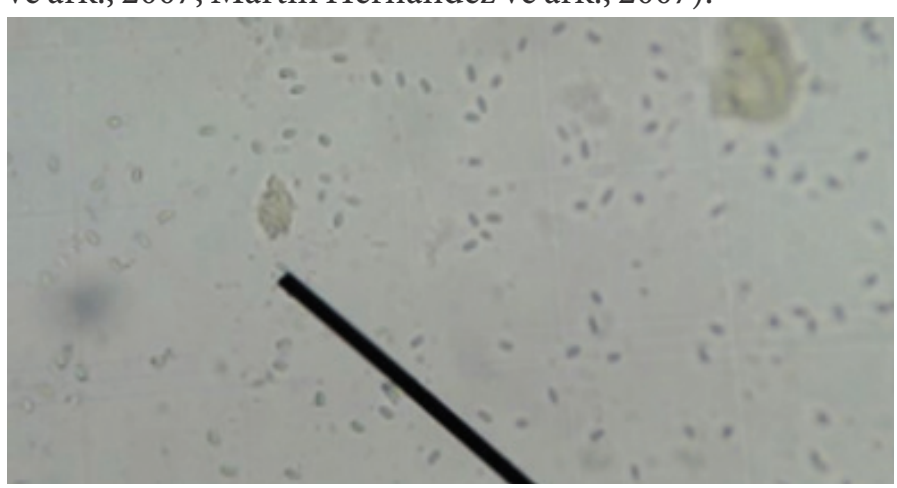

Şekil 1. Nosema sporları $(\times 400)$ (Orijinal)

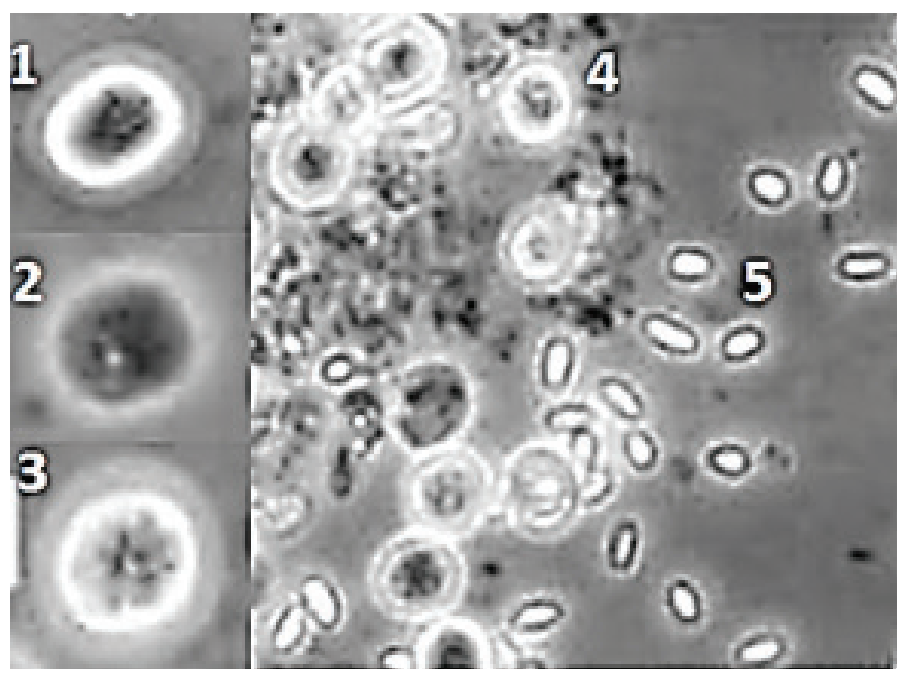

Şekil 2. 1: Olgunlaşmış Malpighamoeba kisti, 2: Malpighamoeba Trofozoiti, 3: Olgunlaşmamış Malpighamoeba kisti, 4: Malpighamoeba kistleri, 5 Nosema sporları. (Santiago ve Lange, 2010)

$\mathrm{Bu}$ mantarları ayıran bir diğer özellik de gelişim süreleridir. Gelişim süresi N. apis'te beş gün iken $N$. ceranae'de ise üç gündür. Yapılan çalışmalarda Nosemosis sporlarına sadece sindirim sistemi epitel hücrelerinde değil bunun yanı sıra Malpighi tüplerinde, tükürük bezlerinde ve yağ dokuda rastlanmıştır (Chen ve Huang, 2010). Enfeksiyon potansiyelini kraliçe arının zayıflaması, kovan içindeki mikro iklimin değişmesi, yeterli miktarda besin ve polen olmaması arttırır. Hastalığın semptomları şişmiş mide ve orta bağırsakta griden beyaza renk değişimidir. A. mellifera’da $N$. ceranae enfeksiyonlarında dört safha belirlenmiştir (Hi-ges ve ark., 2008). İlk safha asemptomatik olup ilkbahardan erken sonbahara kadar 
sürer. İkinci safha geç sonbahardan ilkbahara kadar sürer. rejenerasyon gerçekleşememektedir ve bu durumlara Arılar sıcaklığın düşmesine bağlı olarak enerji stresine girer bağlı olarak erken ölümlerin ortaya çıktığı gösterilmiştir ve ölmeye başlar ve kraliçe arı kolonideki bu kaybı (Dussaubat ve ark., 2012). Bal arısının normal giderebilmek için daha fazla yumurta verir. Arı defekasyonunda dışkı genellikle ince, ortalama $1 \mathrm{~cm}$ popülasyonu değişmez fakat kuluçka miktarı artar. Kraliçe uzunluğunda ipliksi görünümde olup ishalli bal arısının arı kışın yumurta verir. Bu olayda koloni sağlığının iyiye dışkısı ise ortalama $0,5 \mathrm{~cm}$ çapında yuvarlak, düştüğü gittiği gibi bir yanlış yorumlamaya neden olur. Üçüncü noktaya yayılan sulu bir görünüm sergilemektedir. Bal safhada ise kovan popülasyonu yüksektir ve tüm çerçeveler arılarında defekasyon normal şartlarda kovan di-şında kuluçka ile doludur. Koloni popülasyonu yüksek olmasına gerçekleşmekte, mevsim şartlarının uçmaya elverişli rağmen arılar salkım oluşturamaz. Son safha ise ani olarak olmadığı dönemlerde defekasyon ertelenmektedir (Bailey, tüm kovanın çöküşüdür. Bu safha genelde son baharda ve 1955).

erken kış periyodunda gözlemlenir. Son safhadan az Enfeksiyonun başlangıcı klinik olarak genellikle fark edilmiktarda arı ve kraliçe arı ve bir miktar kuluçka kurtulabilir, mez ancak paraziteminin şiddetine bağlı olarak zamanla kurtulan bu bireyler de az virulent enfeksiyonlarla uçamayan ancak önceleri yürüyen arılar, daha sonra builkbaharda çökebilir. Bakıcı arılarda mikrosporodial lunduğu noktada uzun süre bekleyen, zorlukla yürüyebienfeksiyonlarda sporlar farengeal bezlere yerleşir. $\mathrm{Bu}$ len, son zamanlarda ise yürüyemeyen ve paraliz tablosu bezlerin zarar görmesi ile arı sütü üretimi sekteye uğrar sonunda ölü olarak bulunurlar. Kış salkımı teşekkülünden bu durum da kraliçe arının beslenmesini olumsuz etkiler. önce N. ceranae ile enfekte olan kolonilerde hızla gelişen $N$. cerenae enfeksiyonları hızlı gelişir ve oldukça patolojik tablo neticesinde abdomende artan iç basınç ve ölümcüldür. Arılar enfeksiyondan sonraki sekiz gün ishale bağlı olarak kış salkımının bozulması, kovan dışına içerisinde ölür (Higes ve ark, 2007). N. apis ile çıkan bal arılarının geri dönemeyerek öldükleri bildirilenfekte arılıklar incelendiğinde özellikle kovan üst kapağı mektedir (Muz ve ark., 2012).

ve uçuş tahtasında, çok daha ciddi salgınlarda ise kovanın Nosemosise eşlik eden etkenler; Malpighamoeba mellifitamamında hatta çerçeve yüzeylerinde bile ishalli dışkı cae (Protozoon) ve Cryptococcus neoformans var. grubii izlerine ve kirlenmeye rastlanmaktadır. N. cerenae (Mantar) virülensi ve mortaliteyi artırmaktadırlar (Santienfeksiyonlarında ise N. apis enfeksiyonlarının aksine ishal ago ve ark., 2010). Özellikle siyah ana gözü virüsü birçok gözlemlenmez ve bu yüzden $N$. cerenae enfeksiyonları olguda Nosemosise eşlik etmektedir. Apis melliferảnın kuru Nosemosis olarak adlandırılır (Mayack ve Naug, 2009). bağırsak epitel hücreleri hem N. cerenae hem de DWV N. cerenae, N. apis' e göre sıcaklık değişikliklerine daha etkili (Kanat Deformasyon Virusu) tarafından tercih adapte olma yeteneğine sahip olup $25^{\circ} \mathrm{C}-37^{\circ} \mathrm{C}$ sıcaklık edilmektedir. Bu patojenler bağırsak epitel hücreleri için aralığında $N$. ceranae’ nın yaşam çemberini ta- yarışmaktadır. Bu durum sonuç olarak bağırsaklardaki $N$. mamlayabilme yeteneği $N$. apis' inkinden fazladır. Optimal cerenae spor miktarı ile DWV yükü/miktarı arasında ters $33^{\circ} \mathrm{C}$ derecede $N$. cerenae' nin intestinal epiteliyal orantı oluş-turmaktadır (Costa ve ark., 2011; Dainat ve hücrelere zarar verme kapasitesi N. apis' ten 2-3 kat daha ark., 2012).

\section{fazladır. N. ceranae enfeksiyonları yıl boyu asemptomatik Hastalığın Türkiye'deki Yayılışı}

gözlem-lenirken N. apis enfeksiyonları sıcak aylarda, Nosemosisin yaygınlığı klasik metotlar ile yapılan araştırözellikle bal hasadının başında gözlemlenir.

\section{Patojenite}

malarda Bursa yöresinde \%26 (Aydın ve ark., 2001), Kars Nosema sporları konağın hemolenf besin dengesini etkile- yöresinde \%8,7 (Şimşek H, 2005), Muğla bölgesinde \%100 mektedir. N. ceranae’ nin bal arılarında oluşturduğu enerji (Şimşek D, 2007), Trakya bölgesinde \%6.5 (Doğaroğlu ve stresi N. apis'e kıyasla çok daha fazladır. Bu parazitin N. Sıral, 2005) ve Hatay yöresinde \%10 (Muz ve ark., 2012) apis' ten çok daha hızlı gelişerek aynı sürede daha fazla oranlarında bildirilmiştir sayıda hücreyi enfekte etmesiyle her bir hücre içerisinde Hastalığın Dünyadaki Yayılışı

daha fazla sayıda spor oluşması, parazitin doku Türkiye’nin sınır komşusu olan Bulgaristan’da 94 adet arıözgünlüğünün az olması yani bağırsak dışındaki tüm lıktan, 396 adet kovan örneklenmiş, bu arlıklardan dokularda bulunması, enfekte bal arılarının hızla ölmesine 42'sin-de mikroskobik pozitiflik, 47'sinde ise PCR metodu neden olmaktadır (Mayack ve Naug, 2009). N. ceranae ile ile N. ceranae, 2 örnekte ise N. apis pozitifliği tespit enfekte olan kolonilerde homeostazisi sürdüren genlerin edilmiştir (Gurgulova ve ark., 2010). Yunanistan’da koloni baskılanması nedeniyle bağırsaklarda rutin kaybına uğrayan on farklı arılığın dokuzunda N. ceranae 
tek başına, ikisinde N. apis ile miks enfeksiyon şeklinde Serolojik Tanı

PCR metodu ile tespit edilmiştir (Hatjina ve ark., 2011).

Yunanistan'da yapılan bir başka araştırmada 37 arılıktan 27’si N. cerenae pozitif bulunmuştur (Bacandritsos ve ark., 2010). İspanyada yapılan bir araştırmada, bal örneklerinin N. ceranae sporları ile kontaminasyonunun 1988 yllından 2011 yllına kadar artarak devam ettiği bildirilmektedir (Botias ve ark., 2012). İran'ın kuzeybatısındaki 294 arılıktan 72'sinde Nosemosis tespit edilmiştir (Lotfi ve ark., N. ceranae'nin ilk moleküler tanısı 2004 yılında yapılmıştır 2009). Hollanda'da, Nosema ile enfekte kolonilerin \%10 'unun $N$. apis, \%87'sinin ise $N$. ceranae olduğu bildirilmiştir (Van der Steen ve ark., 2010). Avusturya'da 126 arıliktan 59'u Nosema pozitif bulunmuş, bunlardan \% 30'u N. ceranae, \%10'u N. apis, \%60'ı ise miks enfeksiyon evresindeki etkenlerin tür ayrımlarının yapılmasında altın olarak kayıt edilmiştir (Derakhshifar ve ark., 2010). İtalya'da standart olarak kabul edilmektedir (Chen ve ark., 2009; 234 arılıktan 136's1 N. ceranae pozitif bulunurken, bir adet Gisder ve ark., 2010).

N. apis pozitifliği tespit edilmiştir (Granato ve ark.,2010).

\section{Elektron mikroskop tanı}

Polar fiamentin sayısı $N$. apis ve N. ceranae'nın ayırıc1 taHastalığın Tanısı; İnspeksiyon ile makroskobik tanı nısında taksonomik bir ölçü olarak bildirilmiştir. N. ceraGüvenilirliği çok düşük bir yol olup, bu amaçla bal arısı nae’nın 18-21 adet (Chen ve ark., 2009), N. apis'in 20-23 bir elin parmakları yardımıyla toraks kısmından tutulur. adet (Fries, 2010) filament yapıya sahip olduğu tespit edilAbdomenin altıncı tergiti yani iğnenin bulunduğu en son miştir.

halka diğer elin iki parmağı, iki tırnak ucu veya penset yardımı ile tutularak, abdomenin beşinci tergiti ile bağlantısı

\section{Hücre Kültürü İle Hibridizasyon}

koparılıp sindirim sistemi organları dışarıya çekilerek çı- Nosema türlerinin vejatatif formu, Lepidoptera takımında kartılır. Taze arı örneklerinin kullanılması büyük kolaylık yer alan Lymantria dispar türüne ait olan IPL-LD-65Y hesağlamaktadır. Nosema ile enfekte sindirim sisteminde ba- terolog hücre hatlarında, türe özgü olarak floresan in-sitü ğırsaklar timpanik, orta bağırsak kısmı süt beyazı rengi hibridizasyon (FISH) tekniği ile gösterilebilmekte, meroalabilirken, sağlıklı olanları doğal kahvemsi ton gonial evredeki klasik iğ şeklindeki merontların yanı sıra görünümdedir. Makroskobik tanı ölçülerine kesinlikle yuvarlak, oval veya pleomorfik şekillerde tespit edilebilgüvenilmemeli sadece ön fikir verme noktasında tutulmalı, mektedir. Hibridizasyonda floresan işaretli özgün oligokoruma veya tedavi amacıyla mutlaka mikroskobik nükleotitler ve floresan mikroskobisi kullanılmaktadır. $N$. laboratuvar tanısına gidilmesi önerilmektedir (Zeybek, ceranae hedef doku ve hücrelere N. apis kadar özgün değil1991; Aydın, 1994).

\section{Mikroskobik Tanı}

dir. Bu özelliği özgün hücre hattına olan bağımlılığı azaltmakta, daha kolay üretilebilmektedir (Visvesvara, 2002; Gisder ve ark., 2010).

25 adet tarlacı arıya ait abdomen gövdeden ayrılarak temiz bir tüp içerisindeki $25 \mathrm{ml}$ distile su ile homojen hale getirilir. Bu karışımdan bir damla alınarak lam lamel arasında $X$ 400 büyütmeli ş̧ık mikroskobunda muayene edilirNosema sporları lam lamel arasında her iki ucu yuvarlanmış, oval silindirler şeklinde, aktif hareket kabiliyeti olmayan b mermi görünümüne benzetilebilir (Şekil 2) (Zeybek, 1991 Aydın, 1994).

\section{Boyama İle Tanı}

Safranin ve Nigrosin boyaları kullanılabilir (Zeybek, 1991; Aydin, 1994).

\section{Koruma ve Kontrol}

Parazit koloniler arasında horizontal bulaşma (per os) ile yayılmaktadır. Kışlatma alanlarında bulunan güçlü kolonilerin, Nosemosisli zayıf kolonileri yağmalaması, Nosema sporlarıla kontamine balın sağlıklı koloniye bulaşması ile sonlanmaktadır. Farklı kovanlara ait malzemelerin yer degiştirmesi, zayıf ve güçlü koloniler arasında çerçeve değişimi ile arıcılık gereçlerinin müşterek kullanımı sporların ve amip etkeni kistlerin yayılmasında rol oynamaktadır (Malone ve ark., 2001). Ar1 kolonilerinde kullanılan petek ve çerçevelerin uzun süre değiştirilmeden kullanılması, steri- 
lizasyonu sorunlu olan peteklerdeki Nosema spor yükünü arttırmakta, dolayısıyla kışlatma sonu ilkbahar kayıpları ve koloni kayıplarında artış meydana gelmektedir (Fries, 1988). Koruma ve tedavi amaçlı kullanılan ilaçların yararlı olabilmesi için Nosema sporları ile kontamine şerbet, su, kek, polen gibi gıda maddeleri, kovan içi ve dışı tüm mal-zemeler mutlaka değiştirilmelidir. Aksi takdirde sadece Nosema'nın aktif formuna karşı kısa vadeli tedavi ve koruma sağlanmış olacak ancak ilaçların etki etmediği spor form sayesinde sürekli olarak reenfeksiyonlar şekillenerek ilaç uygulamaları uzun dönemde başarısız kalacaktır. Kovan ve kullanılan malzemelerin asetik asit (sirke) ile dezenfeksiyonu sezon öncesi ve sonrasında mutlaka uygulanmalı, her kovanın içine bir adet el demiri asılarak, farklı kovanlarda aynı malzemeler ortak olarak kullanılmamalıdır. Asetik asit Nosema'nın aktif formlarına karşı oldukça etkilidir ancak spor formuna karşı etkili değildir. Hasta arılar için $2 \mathrm{~kg}$ toz şeker / 1 lt sudan oluşturulan şuruba $25 \mathrm{mg}$ fumagillin içeren ilaç eklenerek hazırlanan sıvı (5 lt şurup için $100 \mathrm{mg}$ ), şurupluk vasıtasıyla ağız yoluyla arılara uy-gulanır. Ancak Fumagillin kullanımı günümüzde Avrupa ve ülkemizde yasaklanmıştır. Tedavi sürecinde arılar için hazırlanan vitamin/destek preparatları verilebilir. Bal arı-larını Nosema hastalığına karşı korumak için timol bileşiği içeren 1 lt kekik suyu (kara kekik - zahter (Thymbra spicata), 2 kısım şeker:1 kısım su oranında hazırlanmış 8 It şeker şurubuna katılarak kovan başına 0,5 litre olacak şekilde şurupluk içinde bir hafta arayla iki kez verilir. Uygulama erken ilkbahar ve geç sonbaharda yapılmalıdır.

Sonuç olarak Nosemosis bal arılarında ülkemizde ve Dünya'da arı yetiştiricileri ve arı uzmanları tarafından her zaman dikkate alınması gereken, yıl boyu koruma ve kontrol metotları geliştirilmesi gereken ciddi bir hastalıktır.

\section{Kaynaklar}

Aronstein KA, Saldivar E, Webster TC. Evaluation of Nosema ceranae spore-specific polyclonal antibodies. J Apic Res, 50(2): 145-151, 2011.

Aydın L. Nosemiasis. Türkiye Parasitol Derg, 18(2): 224-228 (1), 1994.

Aydın L, Güleğen E, Çetinbaş H. Bursa yöresi bal arılarında Nosema apis' in (Zander, 1909) yaygınlığı. Türkiye 3 Arıcılık Kongresi Çukurova Üniv Ziraat Fak, Adana, 2001.
Aydın L, Güleğen E, Çakmak İ, Girisgin O, Wells H. Relation between Nosema and Chalkbrood diseases, and its implication for an apiary management model. Bull Vet Inst Pulawy, 50: 471-475, 2006.

Bailey L. Nosema apis and dysantery of the honeybee. J Apic Res, 6: 121-125, 1955.

Bacandritsos N, Granato A, Budge G, Papanastasiou I, Roinioti E, Caldon M, Falcaro C, Gallina A, Mutinelli F. Sudden deaths and colony population decline in Greek honey bee colonies. J Invertebr Pathol, 105: 335-340, 2010.

Botías C, Martín-Hernández R, Garrido-Bailón E, González-Porto A, Martínez-Salvador A, De La Rúa P, Meana A, Higes M. The growing prevalence of Nosema ceranae in honey bees in Spain, an emerging problem for the last de-cade. Res Vet Sci, 93: 150-155, 2012.

Chaimanee V, Wrrit N, Chantaannkul P. Infections of Nosema ceranae in four different honeybee species. J Inver-tebr Pathol, 105(2): 201-210, 2010.

Chen Y, Evans JD, Smith BI, Pettis JS. Nosema ceranae is a long present and wide-spread microsporidian infection of the Europan honey bee (Apis mellifera) in the United States. J Invertebr Pathol, 97(2): 186-188, 2008.

Chen YP, Evans JD, Murphy C, Gutell R, Zuker M, Gun-densen-Rindal D, Pettis JS. Morphological, moleculer, and phylogenetic characterization of Nosema ceranae, a mic-rosporidian parasite isolated from the European honey bee, Apis mellifera. J Eukaryot Microbiol, 56: 142-147, 2009.

Chen YP, Huang ZY. Nosema ceranae, a newly identified pathojen of Apis mellifera in the USA and Asia. Apido-logie, 41(3): 364-374, 2010.

Costa C, Tanner G, Lodesani M, Maistrello L, Neumann P. Negative correlation between Nosema ceranae spore loads and deformed wing virus infection levels in adult honey bee workers. J Invertebr Pathol, 108(3): 224-5, 2011.

Cox-Foster DL, Conles S, Holmes EC, Palacios G, Evans JD, Moran NA, Quan PL, Briese T, Hornig M, Geiser DM, Martinson V, Vanengelsorp D, Kalkstein AL, Drysdale A, Huı J, Zhai JH, Cui LW, Hutchison SK, 
Simons JF, Egholm M, Pettis JS, Lipkın WI. Ametagonic survey of microbes in honey bee colony collapse disorder. Science, 318(5848): 283-287, 2007.

Dainat B, Evans JD, Chen YP, Gauthier L, Neumann P. Predictive markers of honey bee colony collapse. PLoS One, 7 (2): e32151, 2012.

Derakhshifar I, Köglberger H, Oberlerchner J, Moosbeckhofer R. Incidence of Nosema spp. and colony performance in Austria 2006-2008. COST Action FA0803 Prevention of honeybee Colony Losses, Nosema disease: lack of knowledge and work standardization, 2010.

Doğaroğlu M, Siralı R. Survey results on honeybee pests and diseases in Thracian Region of Turkey. Uludag Bee J, 5: 71-78, 2005.

Dussaubat C, Brunet JL, Higes M, Colbourne JK, Lopez J, Choi JH, Martin-Hernandez R, Botias C, Moritz RF, Le Conte Y, Alaux C. Gut pathology and responses to the microsporidium Nosema ceranae in the honey bee Apis mellifera. PLoS One, 7(5): e37017, 2012.

Forsgren E, Fries I. Comarative virulence of Nosema ceranae and Nosema apis in individual European honey bees. Vet Parasitol, 170(3-4): 212-217, 2010.

Fries I. Comb replacement and Nosema disease (Nosema apis) in honeybee colonies. Apidologie, 19: 343-356, 1988.

Fries I. Nosema ceranae in European honey bees (Apis mellifera ). J Invertebr Pathol, 103 Suppl 1: S73-9, 2010.

Gisder S, Hedtke K, Möcke IN, Frielitz MC, Linde A, Genersch E. Five-year cohort study of Nosema spp. in Germany: does climate shape virulence and assertiveness of Nosema ceranae? Appl Environ Microbiol, 76 (9): 3032-8, 2010.

Granato A, Caldon M, Falcaro C, Mutinelli F. Presence of Nosema apis and Nosema ceranae in Italian apiaries. COST Action FA0803 - Prevention of honeybee colony losses, Nosema disease: lack of knowledge and work standardization, 2010.
Gurgulova K, Valchovski R, Petrov P, Ivanova E. Distribution of Nosema apis and Nosema ceranae in Bulgaria. Diagnostic in honeybees. From sampling to data analyses. Beedoc - Cost Action. Ghent University, Belgium, 2010.

Hatjina F, Tsoktouridis G, Bouga M, Charistos L, Evangelou V, Avtzis D, Meeus I, Brunain M, Smagghe G, de Graaf DC. Polar tube protein gene diversity among Nosema ceranae strains derived from a Greek honey bee health study. J Invertebr Pathol, 108(2): 131-4.s, 2011.

Higes M, Garcia-Palencia P, Martin-Hernandez R, Aranzazu M. Experimental infection of Apis mellifera honey bees with Nosema ceranae (Microsporidia). J Invertebr Pathol, 94(3): 211-217, 2007.

Higes M, Martin Hernandez RE, Garrido-Bailon E, Garcia-Palencia P, Meana A. Detection of infective Nosema ceranae (Microsporidia) spores in corbicular pollen of forager honeybees. J Invertebr Pathol, 97(1): 76-78, 2008.

Klee J, Beasana AM, Genersch E, Gisder S, Nanetti A, Tam DQ, Chinh TX, Puerta F, Ruz JM, Kryger P, Message D, Hatjina F, Korpela S, Fries I, Paxton RJ. Widespread dispersal of the microsporidian Nosema ceranae an emergent pathogen of the western honey bee, Apis mellifera. J Invertebr Pathol, 96(1): 1-10, 2007.

Lotfi A, Jamshidi R, Shahryar HA, Yousefkhani M. The prevalence of Nosemosis in honey bee colonies in Arasbaran Region Iran. American-Eurasian J Agric \& Environ Sci, 5: 255-257, 2009.

Malone LA, Gatehouse HS, Tregidga EL. Effects of time, temperature, and honey on Nosema apis (Microsporidia: Nosemstidae), a parasite of the honeybee, Apis mellifera (Hymenoptera: Apidae). J Invertebr Pathol, 77 (4): 258-68, 2001.

Martin-Hernandez R, Meana A, Prieto L, Salvador AM, Garrido-Bailon E, Higes M. Outcome of colonization of Apis mellifera by Nosema ceranae. Appl Environ Microbiol, 73(20): 6331-6338, 2007.

Mayack CH, Naug D. Energetic stress in the honey bee Apis mellifera from Nosema ceranae infection. J Invertebr Pathol, 100: 185-188, 2009. 
Muz MN, Girişgin AO, Muz D, Aydin L. Molecular dete- Webster TC, Pomper KW, Hunti G, Thacker EM, Jones ction of Nosema ceranae and Nosema apis in colony col- SC. Nosema apis infection in worker and queen Apis lapsed apiaries of Turkey. J Apic Res, 49(4): 342-344, mellifera. Apidologie, 35(1): 49-54, 2004.

2010.

Muz MN, Solmaz H, Yaman M, Karakavuk M. Kış Salkımı Erken Bozulan Arı Kolonilerinde Paraziter ve Bakteriyel Patojenler. YYU Vet Fak Derg, 23(3): 147-150, 2012.

Paxton R, Klee J, Korpela S, Fries I. Nosema ceranae has infected Apis mellifera in Europe since at least 1998 and may be more virulent than Nosema apis. Apidologie, 38(6): 558-565, 2007.

Paxton R. Does infection by Nosema ceranae cause Colony Collapse Disorder in Honey bees (Apis mellifera)? J Apic Res, 49: 80-84, 2010.

Santiago P, Lange CE. Detection of Malpighamoeba mellificae (Protista: Amoebozoa) in Apis mellifera (Hymenoptera: Apidae) of Argentina. Rev Soc Entomol Argent, 69 (3-4): 299-303, 2010.

Şimşek H. Elazığ yöresi bal arılarında bazı parazit ve mantar hastalıklarının araştırılması. Ankara Üniv Vet Fak Derg, 52: 123-126, 2005.

Şimşek D. Muğla ili bal arılarının (Apis mellifera) mikrobiyal ve paraziter hastalıklar yönünden incelenmesi. H Ü Fen Bilimleri Enstitüsü, Y üksek Lisans Tezi, 2007.

Topçu B, Arslan MÖ. The prevalence of Nosemosis in honey bee in the province of Kars. Uludağ Bee J, 164-170, 2004.

Ütük AE, Pişkin Ç, Kurt M. Türkiye'de Nosema ceranae’nın ilk moleküler tanısı. Ankara Üniv Vet Fak Derg, 57: 275-278, 2010.

Van der Steen J, Cornelissen B, Blacquière T. Strategy to control bee diseases in the Netherlands. Diagnostic in honeybees. From sampling to data analyses. Beedoc Cost Action. Ghent University, Belgium, 2010.

Visvesvara GS. In vitro cultivation of microsporodia of clinical importance. Clin Microbiol Rev, 15: 401-413, 2002.
Webster TC, Aronstein KA. Nosema ceranae detection by microscopy and antibody test. In: Sammataro D, Yoder JA, editors. Honey Bee Colony Health: Challenges and Sustainable Solutions. Boca Raton, RL: CRC Press. pp, 115-120, 2012.

Zeybek H. Arı Hastalıkları ve Zararlıları. Tarım ve Köy İşleri Bakanlığı Hayvan Hast Araş Enst Müd, Etlik-Ankara, 1991. 